\title{
INTEGRATED FACTORY MODELLING: USING BIM TO DISRUPT THE INTERFACE BETWEEN MANUFACTURING AND CONSTRUCTION IN FACTORY PLANNING
}

\author{
PETER BURGGRÄF, MATTHIAS DANNAPFEL, DENNIS SCHNEIDERMANN, \\ MATTHIAS EBADE ESFAHANI \& NORA SCHWAMBORN \\ Laboratory for Machine Tools and Production Engineering (WZL), RWTH Aachen University, Germany
}

\begin{abstract}
The interface between construction and production is an area of research with rising importance given its increasing demand for efficiency gains in factory planning and construction planning processes. In fact, nowadays, it is usual for production and surrounding buildings to be planned separately as independent entities. According to the Laboratory for Machine Tools and Production Engineering of RWTH Aachen University, it is against this background that recent factory planning projects have reported cost increases and time delays due to non-transparent information between different planners. Building Information Modelling (BIM) addresses precisely this problem. However, BIM is barely used in projects for production planning of factories. This is critical since factory planning has to deal with more complex planning parameters (due to the technical building equipment) compared to private housing construction or public building construction, where BIM is already being applied increasingly. In order to close this gap, it is first of all important to create transparency within the individual information interfaces between production planning and building planning. This article addresses this issue and identifies major obstacles in interdisciplinary cooperation between building planners and production planners. For this purpose, an interdisciplinary and partially standardised study has been carried out using questionnaires and partly-open expert interviews. The results show scarce implementation in factory planning projects due to (1) missing maturity level specifications and (2) missing data management standards. Both theoretical and practical implications of this study as well as limitations and future directions for research are discussed.
\end{abstract}

Keywords: BIM, factory planning, integrated factory modelling, MEP, integrated planning, production planning.

\section{INTRODUCTION}

With around 10\% of Germany's GDP (Gross Domestic Product), 2.5 million jobs [1] and a growth rate of about $10 \%$ [2], the construction sector is one of the core industries in Germany [3]. However, numerous large-scale projects such as the airport of Berlin-Brandenburg are examples of lack of effectiveness and insufficient productivity [4]. In fact, the productivity of Germany's construction industry still remains at 7.1\% below the crisis level of 2007 [2]. In order to put this apparent contradiction into context, it is necessary to understand the special structure of the German construction sector. Germany takes pride in its division of labour and the associated strong expertise in subareas of planning that are distributed among different stakeholders or companies respectively [5]. It is for that reason that the design and construction process is severely functionally segmented. Numerous companies with often not more than 30 employees are involved [6]. Moreover, the work packages, tasks and chargeable fees of a building project are strictly regulated by the German "Fee Scale for Architects and Engineers" (HOAI) [7] whereas in the UK or the US the charged fees are rather based on a stipulated sum, the time of work done or unit cost [8]. Consequently, it is reasonable to say that especially with regard to the high level of split responsibilities within the design and construction process, the German construction industry is hardly comparable to other countries. Moreover, the industry's level of digitisation is one of the lowest compared to 
other core industries in Germany [5]. It follows that Germany has to catch up with the implementation and industry-adoption of Building Information Modelling (BIM), one of the worldwide main drivers of digital productivity improvement in construction [9]. For this purpose, the German initiative "planen-bauen 4.0" (English: planning-building 4.0) has been founded through various associations and chamber organizations. Its tasks are designing, coordination and supporting the digitisation of the entire value chain of planning, building and operation of buildings in Germany. planen-bauen 4.0 is hence involved in numerous projects in the fields of consultancy, communication and research within ten fields of action. The present paper is to be classified in the field of standardisation. Within this particular field of action, the German Institute for Standardization (DIN) has founded the standards committee "Building Information Modeling" with subordinate working groups to reflect German standardization interests [10]. Moreover, planen-bauen 4.0 played a key role in the development of the "Road Map for Digital Design and Construction" of the Federal Ministry of Transport and Digital Infrastructure in Germany. This roadmap aims at making digital planning and construction the standard nationwide and specifies that, as of 2020, BIM should be applied in all new federal transport infrastructure projects [3].

The authors of this paper adopt the definition of BIM as a methodology that integrates all stakeholders of a construction project by managing a shared building-related database to facilitate planning, construction and facility management in operation [9], [11]. By this, BIM can be a main driver of improved stakeholder collaboration [12], which becomes especially relevant for Germany in face of the facts stated above: projects of the AEC industry (Architecture, Engineering, Construction) require close collaboration even in less fragmented constructions sectors of the UK or the US. Main reasons for that are the hazard of conflicting interests among the projects' stakeholders and numerous interfaces through which complex information is shared. The functional complexity of Germany's AEC industry even intensifies that challenge [13], [14]. It can therefore be concluded that the amount and the level of detail of the information to be exchanged among different planners determines the complexity of the cooperation in a construction project. Compared to private housing, the construction of industrial facilities is particularly challenging due to its interconnected and diverse user perspective. Designing a factory thus poses numerous additional challenges since the specialty of production planning has to be integrated into the project as a further dimension.

Factory planning is the planning of coherent building and production systems. Mutual dependencies are extremely important in this field since the production processes - as the core owner perspective - and the building system directly influence each other. This is an area of research that has been intensively investigated [15], [16]. In current practice, however, the planning of production and its corresponding building are performed separately from each other. In this context, recent projects of the Laboratory for Machine Tools and Production Engineering (WZL) of RWTH Aachen University have shown the necessity to plan the building system and the production system in an integrated way [17], [18]. In fact, there is hardly any research on the integration of the production system as a new dimension in Building Information Modelling (see Section 2). Within the framework of a factory planning project for e.GO Mobile AG (a German manufacturer for electric cars), this novel form of cooperation has been carried out prototypically during the design and construction of new factories [19], [17]. However, it was observed that explicitly during the handover of planning results from one planner or one specialty to another, setbacks in the planning progress were reported due to: 
- Missing semantic information of BIM-objects, especially regarding those from the production model

- Objects and models that are not suitably modelled for the specific state of planning

- Missing transparency over requirements regarding the needed level of detail that a certain planner has to deliver at a specific point of time

- Obstacles regarding the integration of the production system's perspective into Information Delivery Manuals (IDM) and concurrently in Model View Definitions (MVD) [20] in order to fit into the standard workflows of buildingSMART

Since the project at e.GO Mobile AG has only partially taken place in a research environment, this paper wants to explore the main obstacles that exist in integrating the production system as a further dimension into the method of Building Information Modelling in order to create a novel planning method of integrated factory modelling.

The paper thus aims at (1) an open expert study regarding the integration of a production system within Building Information Modelling and (2) at the identification and discussion of research opportunities in this field.

The remainder of the paper is structured as follows: Section 2 substantiates the originality of the research project by presenting current knowledge with regard to the integration of production system planning into Building Information Modelling. Section 3 depicts the expert study as the main research methodology of this paper. The results of the study are summarised in Section 4 leading to a conclusion of the results and an outline of future research activities arising from the expert study's outcome.

\section{ORIGINALITY}

In literature, numerous research activities are dealing with BIM [21]-[23]. These research activities consider the entire lifecycle of a building from design [24], [25] over construction [26], [27] up to operation [28], [29] in a very comprehensive way. In addition to this holistic perspective of an entire lifecycle, a major part of studies analyses and describes the content of the individual lifecycle phases in more detail.

The according research can be observed from two perspectives. On the one hand, it examines different functional planning segments in detail. Studies on functional planning segments can be found, for instance, in the areas of architecture [30]-[33] and HVAC (heating, ventilation, air conditioning) [34]-[38]. On the other hand, many research activities focus on topical case studies. Suitable examples for investigated topical case studies are safety systems [39]-[43], precast concrete [44]-[47] and tunnel projects [48]-[52]. Despite the manifold research activities, it has to be noted that the content of many of these publications mainly focuses on one functional planning segment or one topical case study. The interfaces among different planning disciplines are rarely considered.

Especially the interface between production and building planning is hardly given any investigation in today's literature and the use of BIM in the factory planning process is part of just a short number of publications [13], [15], [19].

The existing research activities and studies analyse neither the problems along with the according optimisation potential of a BIM-based factory planning process nor the interface between the production and building planning. As to our knowledge, there is hence no existing research about the problems and associated optimisation potential in practice regarding the interfaces of factory planning processes. Considering this gap of research, the following study was initialised. 


\section{RESEARCH METHODOLOGY}

The aim of the study is to document deficits in the BIM-based factory planning process and to identify optimisation potentials by validating developed hypotheses and gaining information from interviews.

As depicted in Section 2, the interface between production and building planning is rarely considered in the current literature. For this reason, an open, explorative research approach was selected through a combination of a hypothesis test approach and expert interviews.

The conducted expert study is hence divided into two parts: The first part consists of an online questionnaire in which hypotheses were scrutinised and answered by the experts through the limited response options "correct", "incorrect", "not assessable". These three response options were selected in order to reduce the effort for the experts and to receive as unambiguous and clear answers as possible.

In order to perform a scientifically substantiated expert study, the selection of experts is of crucial importance. The term "expert" is generally understood to represent a person with privileged access to relevant expertise, for example through practical experience [53]. In line with this definition, the expert panel of this study consisted of 11 experts from the specialties of architecture, production planning and $\mathrm{MEP}(\mathrm{H})$ (Mechanical, Electrical, Plumbing, Heating). In order to reduce systematic bias and to comply with the European GDPR (General Data Protection Regulation), anonymity was guaranteed to the participants, which is why the exact names of the companies and interviewees are not mentioned explicitly.

The second part of the study consists of partially open interviews that were conducted to confirm the findings of the first part of the study and to explore further in-depth expertise (see Fig. 1).

Hypotheses can be used to confirm assumptions based on personal experience and to generalise them justifiably [54]. The possibility of time-efficient, simultaneous data collection as well as the low influence of the researcher on the expert were decisive criteria for testing the hypotheses by means of an online survey. The content of the nine hypotheses was generated from literature research and own practical experience. The hypotheses' assessment was thereafter operationalised using the German online platform "SoSci-Survey", which is also presented as a tool in the diagram of Fig. 1.

Based on the evaluated expert responses to the hypotheses, an individual interview guideline was designed for each expert. The interviews can thus be classified as partially standardised. They were realised in one-on-one conversations either via telephone conferences or as in-person interviews and lasted approximately 45 minutes each. The explorative character of the study was deliberately chosen in order to ensure a wide scope and an open perspective when revealing the most challenging elements within the collaboration in factory planning with BIM. The execution and the different steps of the data collection are shown in the K3 flowchart diagram in Fig. 1 [55], [56].

After the transcription of the interviews, a content analysis according to Mayring [57] was conducted. First, the available interview materials (interview transcripts), the situation of the material generation (circumstances of the interviews) and formal characteristics of the interview information are determined in this type of analysis. Based on these preparations, a purposeful and efficient analysis of the content is possible by parsing the relevant interview material into units of knowledge gain. Thereafter, these units are analysed with regard to the research gap which in this context is the documentation and identification of deficits and optimisation potential in the BIM-based factory planning process. As a result of this content analysis, the core findings of the expert study were derived and formulated as main obstacles of the BIM-based factory planning process (see Section 4). 


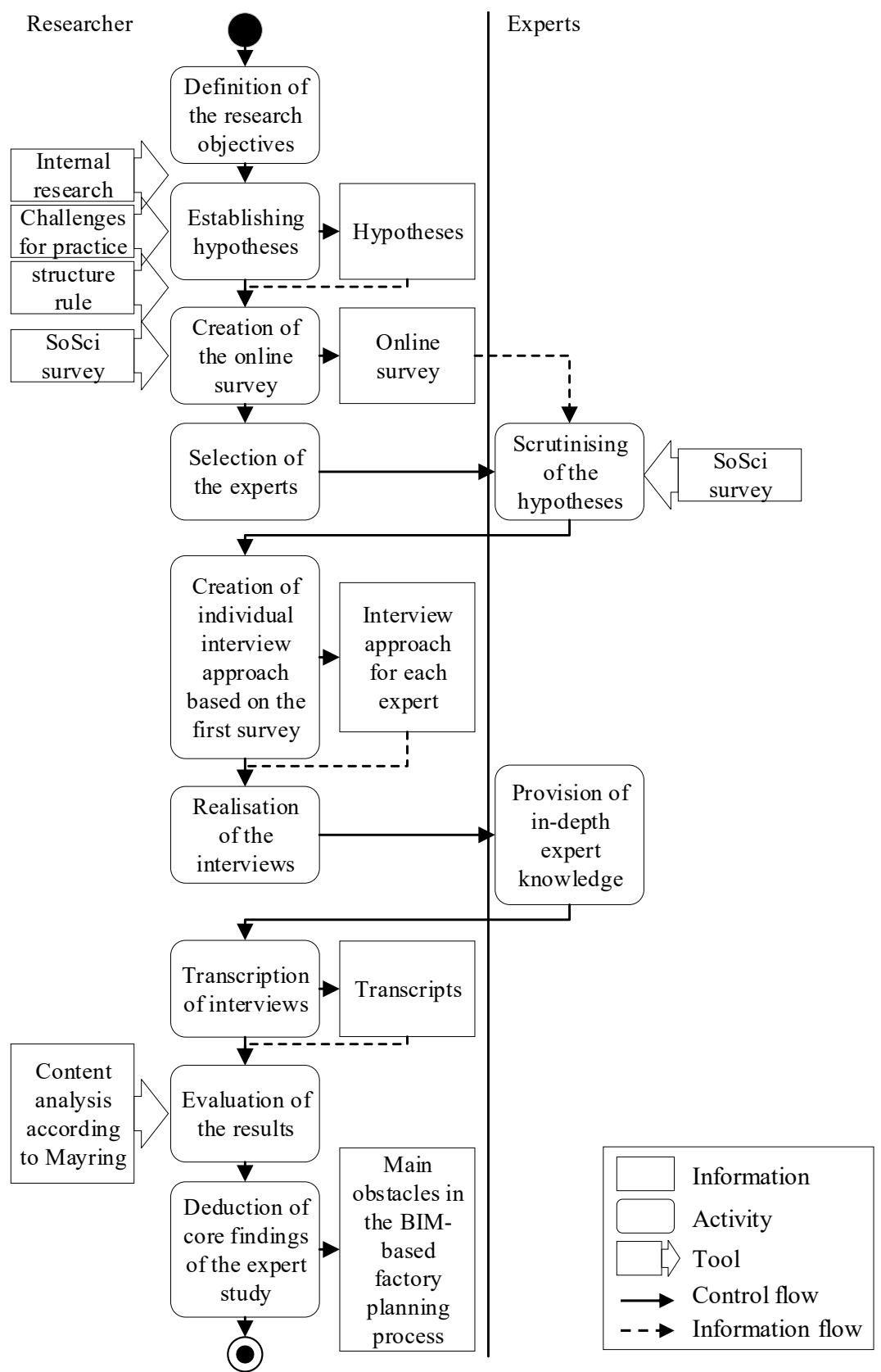

Figure 1: K3 flowchart of the methodology for the expert study.

\section{RESULTS}

In the following, the findings of the expert study are described which can be clustered into three main obstacles occurring in the BIM-based factory planning process or integrated factory modelling, respectively (see Tables 1 and 2). 
Table 1: Assignment of in-depth expert knowledge regarding the main obstacles.

\begin{tabular}{|l|c|}
\hline In-depth expert knowledge on factory planning with BIM & Code \\
\hline The level of building technology of today's factories is constantly rising & $\mathrm{O} 1$ \\
\hline A major part of the costs of a new factory is caused by MEP(H) & $\mathrm{O} 1$ \\
\hline $\begin{array}{l}\text { Slight modifications of planning assumptions can induce significant cost } \\
\text { increases }\end{array}$ & $\mathrm{O} 1$ \\
\hline Part load ratios are often not considered at an early stage of factory planning & $\mathrm{O} 1$ \\
\hline $\begin{array}{l}\text { The actual need of industrial media (e.g. electrical energy, compressed air, } \\
\text { cooling fluid) is less than the installed media capacity }\end{array}$ & $\mathrm{O} 1$ \\
\hline $\begin{array}{l}\text { The level of detail of the transmitted information is insufficient or overly } \\
\text { excessive }\end{array}$ & $\mathrm{O} 1, \mathrm{O} 2$ \\
\hline There is no access to needed information & $\mathrm{O} 2$ \\
\hline Data is untimely provided by upstream planning processes & $\mathrm{O} 2$ \\
\hline There is no maturity model for factory planning in BIM & $\mathrm{O} 2, \mathrm{O} 3$ \\
\hline $\begin{array}{l}\text { There are problems in the transmission of the information regarding } \\
\text { requirement changes }\end{array}$ & $\mathrm{O} 3$ \\
\hline Owners are changing their requirements frequently & $\mathrm{O} 3$ \\
\hline $\begin{array}{l}\text { There are few qualified BIM-coordinators being able to assess modelling } \\
\text { results in factory planning }\end{array}$ & $\mathrm{O} 3$ \\
\hline
\end{tabular}

Table 2: Coding of the main obstacles in the BIM-based factory planning process.

\begin{tabular}{|c|l|}
\hline Code & Main obstacles in the BIM-based factory planning process \\
\hline $\mathbf{O 1}$ & $\begin{array}{l}\text { Inefficient collaboration within the cost-intensive planning interface of MEP(H) } \\
\text { and production/process }\end{array}$ \\
\hline $\mathbf{O 2}$ & Unaligned level of detail in factory planning \\
\hline $\mathbf{O 3}$ & $\begin{array}{l}\text { Lack of transparency regarding the informational relation among the planning } \\
\text { tasks of different specialties and the associated change effects }\end{array}$ \\
\hline
\end{tabular}

\subsubsection{Obstacle $1(\mathrm{O} 1)$ : Inefficient collaboration within the cost-intensive} planning interface of $\mathrm{MEP}(\mathrm{H})$ and production/process

A majority of the interviews revealed that especially $\operatorname{MEP}(\mathrm{H})$ planning is a very complex process in factory planning. Strong interconnections between production processes and $\mathrm{MEP}(\mathrm{H})$ planning demand a strongly collaborative way of planning between those two specialties which is not the case at the moment according to the experts.

The level of building technology of today's factories is constantly rising which is why the major part of the costs of a new factory is caused by $\mathrm{MEP}(\mathrm{H})$. Errors in planning or slight modifications of planning assumptions, for example a change of a few kilowatts of machine energy demand, can hence induce a significant cost increase. Such errors, inter alia, occur from the lack of contact and communication with the owner. In a typical workflow of factory planning in Germany, the $\mathrm{MEP}(\mathrm{H})$ planner acquires the information from the general planner, project leader or sometimes the production planner. These stakeholders, in turn, intend to gather every necessary requirement from the owner; but often not as detailed as required for the $\operatorname{MEP}(\mathrm{H})$ planners. Due to the high cost sensitivity of $\operatorname{MEP}(\mathrm{H})$ planning, however, detailed and precise requirements are needed which in many cases are not provided early enough in the planning process. For instance, production planners often state requirements regarding the temperature of the industrial cooling fluid to a range of $6-8^{\circ} \mathrm{C}$ as this range may in most 
cases not largely influence the production process. For MEP(H) planners, however, this range still leaves a lot of space for cost-relevant cooling capacity calculations.

A certain example of such a need of precise information was mentioned by four different experts: Part load ratios are often not considered at an early stage of factory planning. Due to static calculations, cooling requirements are reported to $\mathrm{MEP}(\mathrm{H})$ planners that are based on, for instance, the maximum demand per machine. During ramp-up, however, those demands are never reached. This actual need of cooling fluid only retrieves a small proportion of the installed cooling capacity. This may not only lead to overinvestment but also to malfunctions and long-term damages on the cooling machine as they are often only designed to be operated within a certain range of load. The experts hence stressed the inefficient collaboration between $\mathrm{MEP}(\mathrm{H})$ planning and production or process planning, respectively. The need for action becomes especially apparent with regard to the planning of electrical and thermal energy.

\subsubsection{Obstacle 2 (O2): Unaligned level of detail in factory planning}

Every planning step of a factory requires the interaction of different planning disciplines. The efficiency of these planning steps depends on the accuracy of the transmitted data and information. The lack of access to needed information hence imposes challenges in collaboration. Every day examples reported by the experts are, for instance, an untimely provision of data by upstream planning processes or the insufficient or overly excessive level of detail of the given information at a certain process point. An integrated planning of a factory can only be performed efficiently if the right information in the right granularity is provided to the correct specialty at the right point within the planning process. Otherwise modifications, clarifications and errors that are detected too late in the process lead to a delay of the whole planning process. At the moment, there is no maturity model for factory planning in BIM, especially regarding the integration of the production planning discipline. Such a maturity model could specify exactly which level of detail is needed at which point of the factory planning process by which other specialty.

An unaligned level of detail of information can thus be seen as one major obstacle in the cooperation of different planning disciplines within factory planning. In this context, the guideline of ISO19650 can be used as a solution basis. For example, ISO suggests using generic model elements or generic information as placeholders before more detailed information is available [11].

\subsubsection{Obstacle $3(\mathrm{O} 3)$ : Lack of transparency regarding the informational relation among}

the planning tasks of different specialties and the associated change effects

In the course of a factory planning project, the owner's requirements are to be fulfilled as precisely as possible. Exactly those owner-given requirements, however, are changed frequently without being able to assess the consequences of those changes within the planning process. The underlying reason is that there is no clear model of the informational dependencies of the factory planning process with BIM.

In coherence with the above-stated lack of maturity models, the change of requirements is another reason for additional expenses and delays caused by extra working steps or the repetition of planning processes. This can be attributed to the fact that requirement changes not only have single-step effects, but can also extend throughout the entire planning process [58].

According to the experts, there are only few proficient BIM coordinators who are able to profoundly and efficiently assess those changes of requirements. A great deal of know-how is necessary to understand the complexity of factory planning processes and to consider all 
relationships of the dynamic requirements pertaining to various specialties such as architecture, production planners or structural engineers.

Following the above, another obstacle is the missing transparency of informational relations among the planning tasks of different specialties and the associated lack of transparency of change effects propagating throughout the whole factory planning process.

\section{CONCLUSION AND FURTHER RESEARCH}

This paper explained the main obstacles when integrating the specialty of production planning into Building Information Modelling. These obstacles are the error-prone and complex interface between $\operatorname{MEP}(\mathrm{H})$ and production planning, the lack of maturity models and the lack of transparency of informational relations (see Table 2).

The research achievements described in this paper are regarded to be novel as factory planning has scarcely been researched within the framework of Building Information Modelling. Despite anticipated efficiency gains, Building Information Modelling has not yet been able to prove itself in factory planning projects. Future research activities should hence focus on overcoming the obstacles analysed in this paper.

For integrating production processes into Building Information Modelling, the transparency of information dependencies between production planning and associated specialties is of crucial importance. The authors hence propose two overarching research steps:

- The information of production planning should be mapped on its most granular level by an ontology-model including all relevant dependencies to other specialties.

- A logical sequence of planning steps should be defined considering necessary and harmonised levels of semantic information and levels of geometry in order to enable an efficient verification of semantic rules such as MEP-relevant calculations [13].

In order to accomplish these steps, the authors are eager to follow the structure of buildingSMART. Against this background, an Information Delivery Manual (IDM) is to be created as a first step [59]. For this purpose, a precise process model is needed that will be based on the already developed Aachen module map of factory planning [15]. This process model should explain planning activities within production planning and establish a logical sequence of those activities. Information exchange requirements form the second step of the development process of Information Delivery Manual. The third part is the definition of functional parts. In this step, information will be categorised and for each exchange, the specific levels of detail will be determined. To enable the integration of the new IDM into software, the IDM elements should be translated into the IFC schema or XML as exchange protocol. Here, existing research results regarding coarse maturity levels of production planning and factory planning from the WZL can be taken as a basis [60].

The need for clearly depicting informational relations and LOD-specific exchange requirements is also included in ISO19650 through the specification for information delivery planning [11]. However, at this point the question can be raised to what extent data standards are the cross-cutting solution or whether in 10 years research and industry will notice that construction projects are so heterogeneous that a reasonable standard can hardly be found. In this case, ISO19650 is a valuable framework for project organization since it provides generic planning and coordination guidelines. The first important step, though, has to be taken for factory planning: creating transparency over information dependencies between production planning and other specialties. According to ISO19650, this basic information model can then serve as a Project's Information Requirement (PIR) for BIM-based factory planning 
which can individually be augmented by project-specific information through the "appointed party" within the Project Information Model (PIM) and Asset Information model (AIM) [11].

One major outcome of the expert study conducted in this paper is the relevance of the interface between production planning and $\operatorname{MEP}(\mathrm{H})$ planning. Research on pure $\mathrm{MEP}(\mathrm{H})$ already exists in the BIM domain. Hu et al. define delivery models in the field of operation and maintenance to foster BIM implementation in large-scale MEP projects [61]. Leite et al. and Wang et al. investigate the influence of different LODs on MEP projects within the framework of BIM, from which especially geometry-related LOD implications for factory planning can be derived [62], [63]. Such already existing approaches are to be integrated into an integrated factory modelling approach which facilitates $\mathrm{MEP}(\mathrm{H})$ and production planning coordination through BIM-based information management.

In Germany, buildingSMART's efforts with regard to factory planning are still limited and tend to refer to BIM in existing buildings. The German MEP group of buildingSMART is currently focusing on a manual for technical guidance for beginners and experts including the introduction of buildingSMART standards and the development of further IDMs. Again, the interface from MEP to architecture is considered rather than to production [64].

Within the expert study, purely static calculations were criticised in particular, as they may result in wrong assumptions regarding requirements for transformers or industrial cooling systems. Therefore, when creating the process models and the associated information maturity models for integrated factory modelling, the highly interdependent calculations of production processes and the associated demands for electrical energy, cooling water, heating capacity, industrial wastewater and compressed air should be taken into focus. In coherence with the lack of qualified BIM coordinators being able to assess an overall factory planning process, such rule-based compliance checks supported by specific simulation software could be automated between the interface of $\operatorname{MEP}(\mathrm{H})$ and production planning and thereby contribute to new progresses within the research of Building Information Modelling.

\section{REFERENCES}

[1] Weitz, H., German Construction Figures 2017, 2018.

[2] European Commission, European Construction Sector Observatory.

[3] Federal Ministry of Transport and Digital Infrastructure, Road Map for Digital Design and Construction, 2015.

[4] PricewaterhouseCoopers GmbH, Baubranche aktuell, Wachstum 2020 Digitalisierung und BIM, pp. 13-15, 2018.

[5] Pilling, A., BIM - das Digitale Miteinander. Beuth Innovation, 1st ed., Beuth Verlag GmbH: Berlin, Wien and Zürich, 2016.

[6] von Both, P., Potentials and Barriers for Implementing BIM in the German AEC Market, 2, pp. 141-142.

[7] HOAI_2013_AKNW, 2013.

[8] Bund Deutscher Architekten Bundesverband, Architects in Germany, Comparing Architectural Practise in English Speaking Countries and Germany, 2011.

[9] Schober, K.-S., Hoff, P., Lecat, A., de Thieulloy, G. \& Siepen, S., Turning point for the construction industry. Roland Berger Focus, pp. 1-24, 2017.

[10] planen-bauen 4.0, Gesellschaft zur Digitalisierung des Planens. https://planenbauen40.de.

[11] Organization and digitization of information about buildings and civil engineering works, including building information modelling (BIM), 19650-1. 
[12] Volk, R., Stengel, J. \& Schultmann, F., Building Information Modeling (BIM) for existing buildings - Literature review and future needs. Automation in Construction, 38, pp. 109-127, 2014.

[13] Ma, Z., Zhang, D. \& Li, J., A dedicated collaboration platform for integrated project delivery. Automation in Construction, 86, pp. 199-209, 2018.

[14] Liu, Y., van Nederveen, S. \& Hertogh, M., Understanding effects of BIM on collaborative design and construction: An empirical study in China. International Journal of Project Management, 35(4), pp. 686-698, 2017.

[15] Schuh, G., Kampker, A. \& Wesch-Potente, C., Condition based factory planning. Production Engineering, 5(1), pp. 89-94, 2011.

[16] Kampker, A., Meckelnborg, P., Burggräf, P. \& Netz, T., Factory planning scrum: integrative factory planning with agile project management. Proceedings of the International Conference on Competitive Manufacturing: COMA 13, Stellenbosch, South Africa, pp. 345-350, 2013.

[17] Burggräf, P., Ebade Esfahani, M., Bertling, M. \& Dannapfel, M., Factory-BIM zur Integrierten Produktions - und Gebäudeplanung, 2018.

[18] Näser, P. \& Wickenhagen, N., Fabrik-integration in das building information modeling (BIM), integration von fabrikplanung und fabrikbetrieb in das building information modeling (BIM). wt Werkstattstechnik online, 108(4), 2018.

[19] Burggräf, P., Dannapfel, M., Schneidermann, D. \& Ebade Esfahani, M., Paradigmenwechsel im fabrikplanungsdatenmanagement. wt Werkstattstechnik online, 109(4), pp. 260-267, 2019.

[20] bSI Standards, www.buildingsmart.org/standards/bsi-standards/.

[21] Alhumayn, S., Chinyio, E. \& Ndekugri, I., The barriers and strategies of implementing BIM in Saudi Arabia. Building Information Modelling (BIM) in Design, Construction and Operations II. BIM 2017, eds S.M. Sener et al., WIT Press: Southampton and Boston, pp. 55-67, 2017.

[22] Tranchant, A., Beladjine, D. \& Beddiar, K., BIM in french SMES: From innovation to necessity. Building Information Modelling (BIM) in Design, Construction and Operations II. BIM 2017, eds S.M. Sener et al., WIT Press: Southampton and Boston, pp. 135-132, 2017.

[23] Turk, Ž., Ten questions concerning building information modelling. Building and Environment, 107, pp. 274-284, 2016.

[24] Mehrbod, S., Staub-French, S., Mahyar, N. \& Tory, M., Characterizing interactions with BIM tools and artifacts in building design coordination meetings. Automation in Construction, 98, pp. 195-213, 2019.

[25] al Hattab, M. \& Hamzeh, F., Simulating the dynamics of social agents and information flows in BIM-based design. Automation in Construction, 92, pp. 1-22, 2018.

[26] Chan, D.W.M., Olawumi, T.O. \& Ho, A.M.L., Perceived benefits of and barriers to building information modelling (BIM) implementation in construction: The case of Hong Kong. Journal of Building Engineering, 25, 100764, 2019.

[27] Volkov, A., Chelyshkov, P. \& Lysenko, D., Information management in the application of BIM in construction: The roles and functions of the participants of the construction process. Procedia Engineering, 153, pp. 828-832, 2016.

[28] Gao, X. \& Pishdad-Bozorgi, P., BIM-enabled facilities operation and maintenance: A review. Advanced Engineering Informatics, 39, pp. 227-247, 2019. 
[29] Ustinovichius, L., Popov, V., Cepurnaite, J., Vilutienè, T., Samofalov, M. \& Miedziałowski, C., BIM-based process management model for building design and refurbishment. Archives of Civil and Mechanical Engineering, 18(4), pp. 1136-1149, 2018.

[30] Pérez-Sánchez, J.C., Mora-García, R.T., Pérez-Sánchez, V.R. \& Piedecausa-García, B., From CAD to BIM: A new way to understand architecture. Building Information Modelling (BIM) in Design, Construction and Operations II. BIM 2017, eds S.M. Sener et al., WIT Press: Southampton and Boston, pp. 45-54, 2017.

[31] Sørensen, N.L., Frandsen, A.K. \& Øien, T.B., Architectural competitions and BIM. Procedia Economics and Finance, 21, pp. 239-246, 2015.

[32] Khodeir, L.M. \& Nessim, A.A., BIM2BEM integrated approach: Examining status of the adoption of building information modelling and building energy models in Egyptian architectural firms. Ain Shams Engineering Journal, 9(4), pp. 1781-1790, 2018.

[33] Herr, C.M. \& Fischer, T., BIM adoption across the Chinese AEC industries: An extended BIM adoption model. Journal of Computational Design and Engineering, 6(2), pp. 173-178, 2019.

[34] Schlueter, A. \& Geyer, P., Linking BIM and design of experiments to balance architectural and technical design factors for energy performance. Automation in Construction, 86, pp. 33-43, 2018.

[35] Gan, V.J.L., Deng, M., Tan, Y., Chen, W. \& Cheng, J.C.P., BIM-based framework to analyze the effect of natural ventilation on thermal comfort and energy performance in buildings. Energy Procedia, 158, pp. 3319-3324, 2019.

[36] Ren, L.-L., Yu, Y.-J. \& Luo, L., Application of the BIM technology in the HVAC design for an office building in Nanjing. MATEC Web Conf., 68(12), 13002, 2016.

[37] Ahern, C., Behan, A., Conway, C.J., Keane, C. \& McCarthy, M., Leveraging lean in construction: A case study of a BIM-based HVAC manufacturing process. Journal of Sustainable Design \& Applied Research, 2(1), 2014.

[38] Sporr, A., Zucker, G. \& Hofmann, R., Automated HVAC control creation based on building information modeling (BIM): Ventilation system. IEEE Access, 7, pp. 7474774758, 2019.

[39] Garzia, F. \& Lombardi, M., The role of BIM for safety and security management. International Journal of Sustainable Development and Planning, 13(1), pp. 49-61, 2018.

[40] Hongling, G., Yantao, Y., Weisheng, Z. \& Yan, L., BIM and safety rules based automated identification of unsafe design factors in construction. Procedia Engineering, 164, pp. 467-472, 2016.

[41] Hossain, M.A., Abbott, E.L.S., Chua, D.K.H., Nguyen, T.Q. \& Goh, Y.M., Designfor-safety knowledge library for BIM-integrated safety risk reviews. Automation in Construction, 94, pp. 290-302, 2018.

[42] Zou, Y., Kiviniemi, A. \& Jones, S.W., A review of risk management through BIM and BIM-related technologies. Safety Science, 97, pp. 88-98, 2017.

[43] Khan, N., Ali, A.K., Skibniewski, M.J., Lee, D.Y. \& Park, C., Excavation safety modeling approach using BIM and VPL. Advances in Civil Engineering, 15, pp. 1-15, 2019.

[44] Kim, M.-K., Wang, Q., Park, J.-W., Cheng, J.C.P., Sohn, H. \& Chang, C.-C., Automated dimensional quality assurance of full-scale precast concrete elements using laser scanning and BIM. Automation in Construction, 72, pp. 102-114, 2016. 
[45] Jeong, Y.-S., Eastman, C.M., Sacks, R. \& Kaner, I., Benchmark tests for BIM data exchanges of precast concrete. Automation in Construction, 18(4), pp. 469-484, 2009.

[46] Guo, E.W., Qian, Y.X. \& Li, C.G., The application of building information model in the design of precast concrete structures. AMM, 716-717, pp. 299-302, 2014.

[47] Costa, G. \& Madrazo, L., Connecting building component catalogues with BIM models using semantic technologies: An application for precast concrete components. Automation in Construction, 57, pp. 239-248, 2015.

[48] Zhi, P., Shi, T., Wang, W. \& Wang, H., Application of BIM technology in the construction management of shield tunnel. 4th International Conference on Information Management (ICIM), pp. 284-289, 2018.

[49] Borrmann, A., Kolbe, T.H., Donaubauer, A., Steuer, H., Jubierre, J.R. \& Flurl, M., Multi-scale geometric-semantic modeling of shield tunnels for GIS and BIM applications. Computer-Aided Civil and Infrastructure Engineering, 30(4), pp. 263281, 2015.

[50] Exinger, C., Mulitzer, G., Felsner, R., Lemmerer, J., Matt, R. \& Griesser, E., BIM pilot project Granitztal tunnel chain: Development of data structures for tunnel structure and track superstructure. Geomechanik und Tunnelbau, 11(4), pp. 348-356, 2018.

[51] Daller, J., Žibert, M., Exinger, C. \& Lah, M., Implementation of BIM in the tunnel design: Engineering consultant's aspect. Geomechanik und Tunnelbau, 9(6), pp. 674683, 2016.

[52] Chen, L., Lu, S. \& Zhao, Q., Research on BIM-based highway tunnel design, construction and maintenance management platform. IOP Conference Series Earth and Environmental Science, 218(1), 12124, 2019.

[53] Meuser, M. \& Nagel, U., The Expert Interview and Changes in Knowledge Production, Palgrave Macmillan, pp. 17-42, 2016.

[54] Bortz, J. \& Döring, N., Forschungsmethoden und Evaluation: Für Human - und Sozialwissenschaftler; mit 87 Tabellen. Springer-Lehrbuch Bachelor, Master, 4th ed., Springer-Medizin-Verl., Heidelberg, 2006.

[55] Killich, S., Luczak, H., Schlick, C., Weissenbach, M., Wiedenmaier, S. \& Ziegler, J., Task modelling for cooperative work. Behaviour \& Information Technology, 18(5), pp. 325-338, 1999.

[56] Kausch, B., Integrative methodik zur grafischen modellierung und ereignisdiskreten simulation von entwicklungsprozessen in der verfahrenstechnik. Zugl.: Aachen, Techn. Hochsch., Diss., 2009. Industrial Engineering and Ergonomics, 7, 2010.

[57] Mayring, P., Qualitative inhaltsanalyse: grundlagen und techniken. UTB für Wissenschaft Pädagogik, Vol. 8229, 9th ed., Beltz: Weinheim, 2007.

[58] Bejjani, C., Utsch, J., Thiele, T., Meisen, T., Jeschke, S. \& Burggräf, P., Flow chart based information modeling for factory planning. Procedia CIRP, 72, pp. 410-415, 2018.

[59] Deutsches Institut für Normung e.V., Bauwerksinformationsmodelle - handbuch der informationslieferungen, teil 1: methodik und format, 35.240.67; 91.010.01, 29481-1.

[60] Krunke, M., Reifegradmanagement in der Fabrikplanung. Dissertation. Ergebnisse aus der Produktionstechnik Produktionssystematik, 2017, Band 17, 1st ed., 2017.

[61] Hu, Z.-Z., Tian, P.-L., Li, S.-W. \& Zhang, J.-P., BIM-based integrated delivery technologies for intelligent MEP management in the operation and maintenance phase. Advances in Engineering Software, 115, pp. 1-16, 2018.

[62] Leite, F., Akcamete, A., Akinci, B., Atasoy, G. \& Kiziltas, S., Analysis of modeling effort and impact of different levels of detail in building information models. Automation in Construction, 20(5), pp. 601-609, 2011. 
[63] Wang, J., Wang, X., Shou, W., Chong, H.-Y. \& Guo, J., Building information modeling-based integration of MEP layout designs and constructability. Automation in Construction, 61, pp. 134-146, 2016.

[64] Building Smart Germany; buildingSMART e.V. www.buildingsmart.de. 